\title{
Correction to: Human Resource Development in Vietnam
}

\author{
Hien Thi Tran, Tam To Phuong, Huyen Thi Minh Van, \\ Gary N. McLean, and Mark A. Ashwill
}

\section{Correction to:}

\section{H. T. Tran et al. (eds.), Human Resource Development in Vietnam, Palgrave Macmillan Asian Business Series, https://doi.org/10.1007/978-3-030-51533-1}

The original version of the book was inadvertently published with minor errors in Front Matter, Chapters 4, 9, and Index, which have now been updated. The corrections to the book have been updated with the changes.

The updated version of these chapters can be found at https://doi.org/10.1007/978-3-030-51533-1_4

https://doi.org/10.1007/978-3-030-51533-1_9 